Psychotherapeut

https://doi.org/10.1007/s00278-021-00548-9

(c) Der/die Autor(en) 2021

\section{Erratum zu: Persönlichkeit, Lebensbedeutungen und Angst vor dem Tod bei affektiven Störungen}

\author{
Paraskevi Mavrogiorgou' $\cdot$ Fabian Chmielewski ${ }^{2} \cdot$ Sven Hanning ${ }^{2} \cdot$ Georg Juckel $^{1}$ \\ ' Klinik für Psychiatrie, Psychotherapie und Präventivmedizin, LWL-Universitätsklinikum der Ruhr- \\ Universität Bochum, Bochum, Deutschland \\ ${ }^{2}$ Privatpraxis für Psychotherapie, Beratung und Coaching, Praxisgemeinschaft am Weiltor, Hattingen, \\ Deutschland
}

Die Online-Version des Originalartikels ist unter https://doi.org/10.1007/s00278-020-00439-5 zu finden.

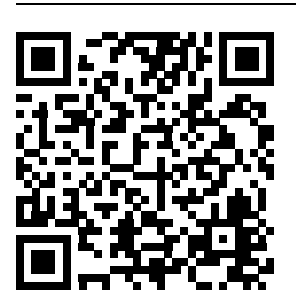

QR-Code scannen \& Beitrag online lesen

\section{Erratum zu:}

Psychotherapeut 2020

https://doi.org/10.1007/s00278-020-

00439-5

Der Artikel Persönlichkeit, Lebensbedeutungen und Angst vor dem Tod bei affektiven Störungen von Paraskevi Mavrogiorgou, Fabian Chmielewski, Sven Hanning und Georg Juckel wurde ursprünglich Online First ohne "Open Access" auf der Internetplattform des Verlags publiziert. Nach der Veröffentlichung in Band 65, Heft 4, pp. 304-312 hatten sich die Autoren für eine „Open Access"-Veröffentlichung entschieden. Das Urheberrecht des Artikels wurde deshalb in (c) The Author(s) 2020 geändert. Dieser Artikel ist jetzt unter der Creative Commons Namensnennung 4.0 International Lizenz veröffentlicht, welche die Nutzung, Vervielfältigung, Bearbeitung, Verbreitung und Wiedergabe in jeglichem Medium und Format erlaubt, sofern Sie den/die ursprünglichen Autor(en) und die Quelle ordnungsgemäß nennen, einen Link zur Creative Commons Lizenz beifügen und angeben, ob Änderungen vorgenommen wurden.

Die in diesem Artikel enthaltenen Bilder und sonstiges Drittmaterial unterliegen ebenfalls der genannten Creative Commons Lizenz, sofern sich aus der Abbildungslegende nichts anderes ergibt. Sofern das betreffende Material nicht unter der genannten Creative Commons Lizenz steht und die betreffende Handlung nicht nach gesetzlichen Vorschriften erlaubt ist, ist für die oben aufgeführten
Weiterverwendungen des Materials die Einwilligung des jeweiligen Rechteinhabers einzuholen.

Weitere Details zur Lizenz entnehmen Sie bitte der Lizenzinformation auf http://creativecommons.org/licenses/by/ 4.0/deed.de.

\section{Korrespondenzadresse}

Prof. Dr. med. Georg Juckel

Klinik für Psychiatrie, Psychotherapie und Präventivmedizin, LWL-Universitätsklinikum der Ruhr-Universität Bochum

Alexandrinenstr. 1-3, 44791 Bochum, Deutschland

georg.juckel@rub.de

Funding. Open Access funding enabled and organized by Projekt DEAL.

Open Access. Dieser Artikel wird unter der Creative Commons Namensnennung 4.0 International Lizenz veröffentlicht, welche die Nutzung, Vervielfältigung, Bearbeitung, Verbreitung und Wiedergabe in jeglichem Medium und Format erlaubt, sofern Sie den/die ursprünglichen Autor(en) und die Quelle ordnungsgemäß nennen, einen Link zur Creative Commons Lizenz beifügen und angeben, ob Änderungen vorgenommen wurden.

Die in diesem Artikel enthaltenen Bilder und sonstiges Drittmaterial unterliegen ebenfalls der genannten Creative Commons Lizenz, sofern sich aus der Abbildungslegende nichts anderes ergibt. Sofern das betreffende Material nicht unter der genannten Creative Commons Lizenz steht und die betreffende Handlung nicht nach gesetzlichen Vorschriften erlaubt ist, ist für die oben aufgeführten Weiterverwendungen des $\mathrm{Ma}$ terials die Einwilligung des jeweiligen Rechteinhabers einzuholen.

Weitere Details zur Lizenz entnehmen Sie bitte der Lizenzinformation auf http://creativecommons.org/ licenses/by/4.0/deed.de. 